\title{
Using the Digital Occlusal Analysis (T-Scan NOVUS) in Diagnosis the MFDS in Iraqi Patients During Lateral Excursion Movements
}

\author{
Sanaa Abdul Hameed Hussein ${ }^{1}$, Jamal N. Ahmed ${ }^{2}$ \\ ${ }^{1}$ Researcher B.D.S M.Sc., ${ }^{2}$ B.D.S., M.S., Ph.D. Prof., College of Dentistry, University of Baghdad, Iraq
}

\begin{abstract}
The aim of the study is to evaluate the effectiveness of digital occlusal analysis (T- scan) in diagnosis the patients with MFDS during lateral excursion movements. Method and materials: participants with full dentition and angle class I relation. Patients diagnosed based on DC/TMD criteria, digital occlusal analysis including (disclusion time, occlusion time) registered by T-Scan NOVUS device during the excursion movements in both (Right and Left) sides. Results: Non-significant differences between the age groups, a significant differences between the gender groups and the females were more prevalent than the males, all the means values of occlusal parameters (disclusion time, occlusion time) were higher in MPDS patients group than healthy control group, Highly significant difference according (disclusion time, occlusion time) are documented between MPDS patients and the healthy control in lateral excursion movements (R \& L). Conclusion: This study concluded, that the digital occlusal analysis measured by $T$ scan Novus devise is a more accurate and objective method in diagnosis the patients with MPDS during lateral excursion movements.
\end{abstract}

Keywords: Occlusion time, disclusion time, occlusal force, MFDS, T-scan, OT, DT, lateral excursion.

\section{Introduction}

Myofascial pain is one of the most common types of chronic muloskeletal pain in clinical medicine ${ }^{(1,2)}$. A hyperirritable spot in a palpable taut band of skeletal muscle fibers, and having MTrPs is necessary to confirm the diagnosis of myofascial pain ${ }^{(3)}$. Several possible mechanisms can lead to the development of myofascial trigger points, including low-level muscle contractions, contractures, direct trauma, muscle overload, postural stress $^{(4,5,6)}$. Dynamic stability in relation to the TMJ is the characteristic of the joint to achieve normal function ${ }^{(7)}$.

T-Scan is a digital occlusion analysis system that records and measures tooth contact, force, and timing

\footnotetext{
Corresponding Author: Sanaa Abdul Hameed Hussein

Researcher B.D.S M.Sc., College of Dentistry, University of Baghdad, Iraq e-mail:dr.sanaa1985@yahoo.com
}

in real-time (8, 9 and 10). The Disclusion Time is defined as the duration of time that working and nonworking molars and premolars are in contact during a mandibular excursive movement ${ }^{(11)}$. The more time taken for excursive movement $(>0.4 \mathrm{sec})$ leads to longer compression of the periodontal ligament, thereby leading to muscle hyperactivity ${ }^{(12)}$. The time reported from the first occlusal contact until reaching the maximum intercuspation is known as Occlusion Time $(\mathrm{OT})^{(13)}$. According to the manufacturer, OT is recommended as less than 0.2 seconds $^{(14,15)}$. OT has been considered as a capable description of occlusion ${ }^{(16)}$.

\section{Method and Materials}

This study was designed and conducted in the department of oral medicine in the teaching hospital of College of Dentistry/University of Baghdad in period from April 2019 to February 2020. The participants were selected according to the Diagnostic Criteria for Temporomandibular Disorders ${ }^{(17)}$ after obtaining ethical approval from the institutional ethical committee and written informed consent. The participants completed 
a self-reported questionnaire, containing information about personal, medical, and dental histories.

Digital occlusal analysis including Disclusion time (DT) and Occlusion time (OT) registered using the T-Scan NOVUS system (T-Scan, Tekscan, Inc., S. Boston, MA, USA) system, shown in figure (1). Subjects with full dentition, Angle class I relation and no history of any systemic diseases related to both groups (patients and controls) which included in this study, while any patient has ongoing treatments or recently treated from TMJ disorders excluded from this study.
Analysis of data was carried out using the available statistical package of SPSS-25. The significance of difference of different means (quantitative data) were tested using Paired-t-test for difference of paired observations (or two dependent means. The significance of difference of different percentages (qualitative data) were tested using Pearson Chi-square test ( $c^{2}$-test) with application of Yate's correction or Fisher Exact test whenever applicable. Statistical significance was considered whenever the $\mathrm{P}$ value was equal or less than 0.05 .

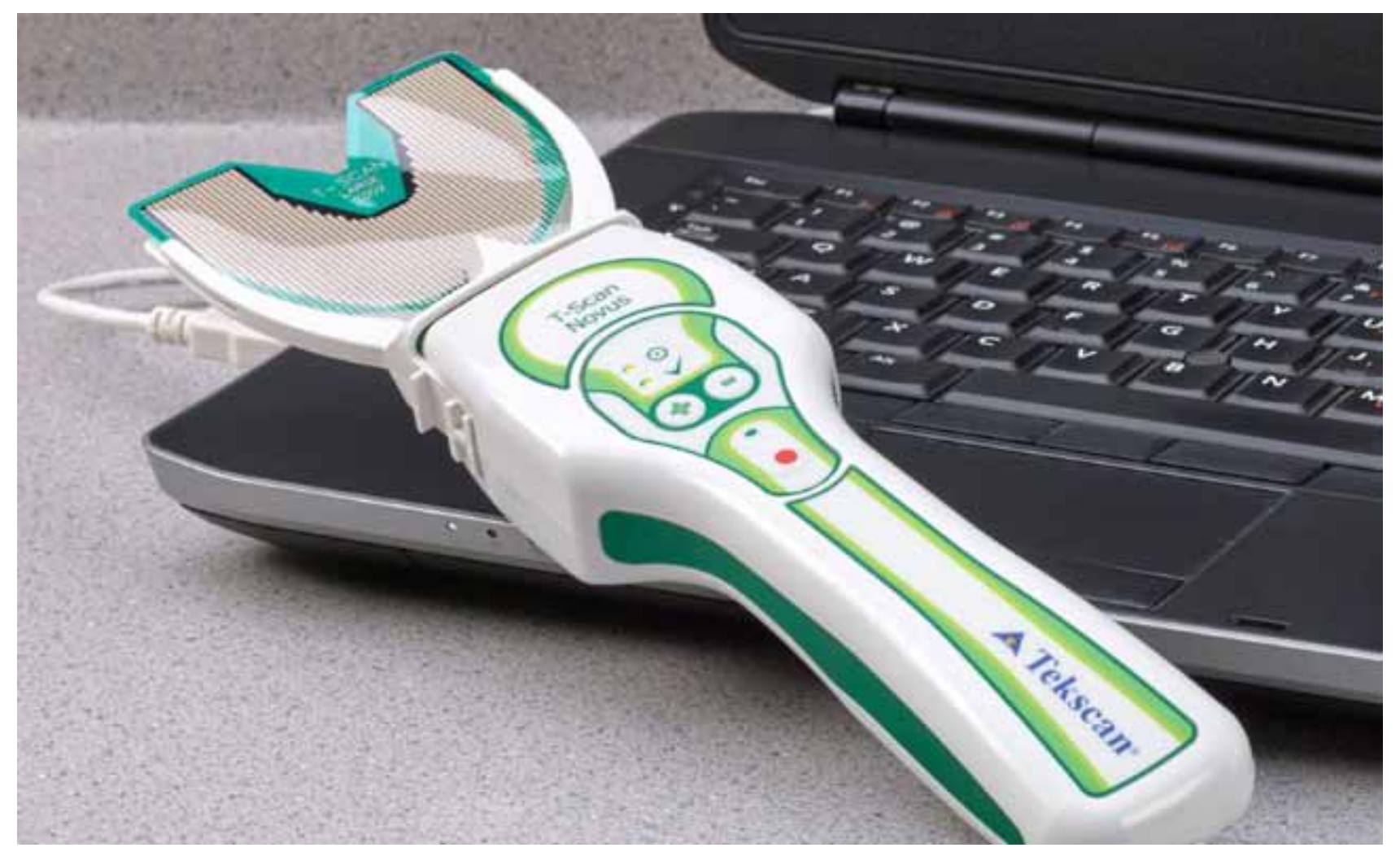

Figure 1: T-Scan (Novus) device

\section{Results}

One hundred and ten (110) participant were included in this study with age range (18-43) years old and divided into two main groups: diseased group (show signs and symptoms of myofacial pain syndrom) with ${ }^{(85)}$ patients and (25) healthy controlled free from signs and symptoms of MPDS. The male: female ratio of the DG was (17:68) and within the control group was (10:15). Table (1) showed the demographic characteristic of the study groups. There were no significant differences $\mathrm{P}>0.05$ according to the age between the two study groups while according to gender this study reported a significant difference $\mathrm{P} \leq 0.05$ and the females were more predominant than males. 
Table (1) Demographic characteristic of the study groups.

\begin{tabular}{|c|c|c|c|c|c|c|}
\hline & & \multicolumn{2}{|c|}{ Diseased group } & \multicolumn{2}{|c|}{ Control group } & \multirow{2}{*}{$P$ value } \\
\hline & & No & $\%$ & No & $\%$ & \\
\hline \multirow{5}{*}{ Age (Years) } & $<20 y$ & 11 & 11.9 & 1 & 4.0 & $0.356^{\mathrm{NS}}$ \\
\hline & $20---29$ & 28 & 33.3 & 10 & 40.0 & \\
\hline & $30---39$ & 31 & 36.9 & 12 & 48.0 & \\
\hline & $=>40 \mathrm{y}$ & 15 & 17.9 & 2 & 8.0 & \\
\hline & Mean \pm SD (Range) & \multicolumn{2}{|c|}{$30.5 \pm 8.3$} & \multicolumn{2}{|c|}{$30.5 \pm 6.3$} & \\
\hline \multirow{2}{*}{ Gender } & Male & 17 & 20.0 & 10 & 40.0 & $0.012^{\mathrm{S}}$ \\
\hline & Female & 68 & 80.0 & 15 & 60.0 & \\
\hline
\end{tabular}

* Significant difference between proportions using Pearson Chi-square test at 0.05 level, NS: Non-Significant, SD: Standard Deviation, No: Number, \% Percentage

Table (2) represented the descriptive Statistics of [Disclusion time test] parameter in the studied groups during lateral excursion movement (Right and left). The results showed the mean values in diseased group were higher than control group also a highly significant difference $\mathrm{P}<0.01$ has been documented between the diseased and control groups.

Table (2) Descriptive Statistics of [Discclusion time test] parameter in the studied groups distributed for different locations

\begin{tabular}{|l|l|c|c|c|c|}
\hline Locations & Groups & No. & Mean & SD & P-vale $^{(*)}$ \\
\hline \multirow{2}{*}{ Right Lateral } & Diseased & 85 & 0.54 & 0.45 & $0.020^{\mathrm{S}}$ \\
\cline { 2 - 6 } & Control & 25 & 0.15 & 0.14 & 0.46 \\
\hline \multirow{2}{*}{ Left Lateral } & Diseased & 85 & 0.69 & 10.69 & $0.056^{\mathrm{S}}$ \\
\cline { 2 - 5 } & Control & 25 & 0.24 & & \\
\hline
\end{tabular}

NO: Number; S: significant $\mathrm{P} \leq 0.05$

As shown in table (3) the occlusion time test parameter showed a significant difference $\mathrm{P} \leq 0.05$ between the diseased group and control group during the excursion movements $(\mathrm{R} \& \mathrm{~L})$ and with average mean values higher in diseased group than control group.

Table (3) Descriptive Statistics of [Occlusion time test] parameter in the studied groups during lateral excursion movements $(R \& L)$

\begin{tabular}{|l|l|c|c|c|c|}
\hline Locations & Groups & No. & Mean & SD & P-vale $^{(*)}$ \\
\hline \multirow{2}{*}{ Right Lateral } & Diseased & 85 & 0.57 & 0.39 & $0.053^{\mathrm{S}}$ \\
\cline { 2 - 6 } & Control & 25 & 0.10 & 0.28 & 0.34 \\
\hline \multirow{2}{*}{ Left Lateral } & Diseased & 85 & 0.45 & 0.16 & $0.036^{\mathrm{S}}$ \\
\cline { 2 - 6 } & Control & 25 & 0.12 & 0.16 \\
\hline
\end{tabular}

S: Sig. at $\mathrm{P}<0.05$, SD slandered deviation, NO: number 


\section{Discussion}

This study illustrated that no differences $\mathrm{P}>0.05$ in age groups while according to the gender a significant difference $\mathrm{P} \leq 0.05$ was reported among studied groups. Also, the study showed MFDS is more common in females than males, with several studies registered a high prevalence of TMDs in females patients ${ }^{(18,19,20)}$ which agree with current study. Pain intensity in women with TMD during the menstrual cycle was the highest and was associated with high concentrations of estrogen ${ }^{(21)}$, this result was in agreement with other recent study reported by (22) that demonstrated the presence of estrogen receptors in women's TMJs changes metabolic functions, increasing ligament laxity. Other potential reasons include neurophysiologic and psychosocial reasons that result in more severe and more frequent pain in females than in males ${ }^{(23)}$. The finding of gender difference $\mathrm{s}$ associating with TMD pain symptoms supports the previous studies $(24,25)$. The previous findings stated that TMD is most common among 20- to 40 -year-olds $(26,27,28)$, and these with agree the present study that showed a significant differences in TMD pain symptoms between age groups, but this study was in contrast with ${ }^{(29)}$. In certain cases of TMD or OFP, the etiology is at least partially related to occlusion in the form of excessive forces on individual teeth (high spots) or interferences to function ${ }^{(30)}$. These conditions can be readily detected by the T-Scan but not by just analyzing marks on the teeth ${ }^{(31)}$. The T-Scan measures both the relative force on each tooth and timing of the contacts, the practitioner can pinpoint any occlusal problem without guessing (32). Prolonged excursive frictional contacts increase the total time PDL mechanoreceptors are compressed in excursive movements, where the PDL compression time is equal to the DT duration of that same excursion ${ }^{(33)}$. The more time the excursive interferences contact, the longer time the PDL are compressed, resulting in prolonged durations of masticatory muscle contractions (34). The fact that mentioned above displayed in current study which all means of the diseased group were higher than the control group this agree with previous study documented by ${ }^{(35)}$. Ciavarella et al., (36) illustrated that the prolonged disoclusion time, frequency of premature contacts and asymmetry in the occlusal force, intracapsular joint disorder lead to various temporomandibular joint related problems and this with agree with current study. Significantly longer disclusion time, higher posterior frictional contacts, and more TMD symptoms were observed in the postorthodontic group, suggesting that orthodontic treatment increases posterior tooth friction. Computerized occlusal analysis is an objective diagnostic tool determining the quality of excursive movements following orthodontic treatment ${ }^{(37)}$.

Specifically, Disclusion Time Reduction (DTR) of all molars and premolars to $<0.5$ seconds per lateral excursion has been shown to reduce muscle hyperactivity levels and their related myogenous symptoms pre to post treatment. Different authors using this technique have reported statistically significant differences in Disclusion Time durations, muscle contraction levels, Time-toMuscle Shutdown durations, and rapid muscular TMD symptom resolutions ${ }^{(38)}$. This study has considered occlusion time (OT) and has shown that the differences between healthy patients and those suffering from MPS were statistically highly significant and the average values of occlusion time were longer in comparison to the control group, The results of this study are similar to the results of studies carried out by Baldini, Nota and Cozza in Italy ${ }^{(39)}$ : occlusion time longer by $0.18 \mathrm{~s}$ was recorded among investigative groups whereas the results were statistically significant,also is agree with Wang and Yin who reported average value of occlusion time was $1.36 \pm 0.03 \mathrm{~s}$ longer than in the control group, whereas the average in patients with TMDs was as high as 2.05 $\pm 0.06^{(40)}$. When compared between current study and Agne Dzingute et al., (41) previous study was in contrary statically but is agree about the TMD group has the average value $0.045 \mathrm{~s}$ longer in comparison to the control group related to OT. The T scan results showed both occlusion time and disclusion time in the patients with TMD disorders are significantly extended than the normal subjects ${ }^{(42)}$.

\section{Conclusion}

This study concluded, MPDS is more prevalent in the females than males, Occlusal parameters included (DT and OT) recorded by digital occlusal analysis (T-scan) showed with more average values in MFDS patients than the control group and a high significant difference $\mathrm{P} \leq 0.01$ recorded between them. So the digital occlusal occlusal analysis measured by $\mathrm{T}$ scan Novus devise is a more accurate and objective method in diagnosis the patients with MPDS during lateral excursion movements.

\section{Conflict of Interest: None}

\section{Funding: Self}

Ethical Clearance: Not required 


\section{References}

1. Shah JP, Thaker N, Heimur J, Aredo JV, Sikdar S, Gerber L. Myofascial trigger points then and now: a historical and scientific perspective. Pm R. 2015;7(7):746-761.

2. Simons DG. New views of myofascial trigger points: etiology and diagnosis. Arch Phys Med Rehabil. 2008;89(1):157-159.

3. Gerwin RD. Myofascial trigger point pain syndromes. Semin Neurol. 2016;36(5):469-473

4. Bron, C., Dommerholt, J. D. (2012). Etiology of myofascial trigger points. Current pain and headache reports, 16(5), 439-444

5. Fernández-de-las-Peñas, C., Cuadrado, M. L., Arendt-Nielsen, L., Simons, D. G., Pareja, J. A. (2007). Myofascial trigger

6. Gerwin, R. D. (2001). Classification, epidemiology, and natural history of myofascial pain syndrome. Current pain and headache reports, 5(5), 412-420.

7. Kuntamukkula, S., Sinha, R., Tiwari, P. K., \& Paul, D. (2018). Dynamic Stability Assessment of the Temporomandibular Joint as a Sequela of Open Reduction and Internal Fixation of Unilateral Condylar Fracture. Journal of Oral and Maxillofacial Surgery. doi:10.1016/j.joms.2018.06.014

8. Davies S, Gray RM. What is occlusion? Br. Dent. J. 2001;191:235.

9. Kerstein RB. T-scan III applications in mixed arch and complete arch, implant -supported prosthodontics. Dent. Implantol. Update. 2008;19:49-53

10. Trpevska V, Kovacevska G, Benedeti A, Jordanov B. T-scan III system diagnostic tool for digital occlusal analysis in orthodontics - a modern approach. Prilozi. 2014;35:155-160. doi: 10.2478/ prilozi-2014-0020

11. Kerstein R. Disclusion time measurement studies: stability of disclusion time: a 1 year follow up. J Prosth Dent. 1994;72:164-8.

12. Prafulla Thumati, Rakhi Manwani, Minal Mahantshetty. The effect of reduced disclusion time in the treatment of myofascial pain dysfunction syndrome using immediate complete anterior guidance development protocol monitored by digital analysis of occlusion. The Journal of Craniomandibular \& Sleep Practice 2014 VOL. 32 NO. 4
Medico-legal Update, January-March 2021, Vol. 21, No. 1

923

13. Kerstein, Robert \& Grundset, K.. (2001). Obtaining measurable bilateral simultaneous occlusal contacts with computer-analyzed and guided occlusal adjustments. Quintessence International. 32. 7-18.

14. Kerstein RB, Wright NR. Electromyographic and computer analyses of patients suffering from chronic myofascial pain-dysfunction syndrome: before and after treatment with immediate complete anterior guidance development. J Prosthet Dent. 1991 Nov;66(5):677-86.

15. Kerstein, R, B. Non-Simultaneous Tooth Contact In Combined Implant and Natural Tooth Occlusal Schemes. Practical Periodontics and Aesthetic Dentistry 2001:13 (9);751-e. 2014; 28(1): 6-27.

16. Cheng, H. J., Geng, Y. \& Zhang, F. Q. [The evaluation of intercuspal occlusion of healthy people with T-Scan II system]. Shanghai kou qiang yi xue=Shanghai journal of stomatology $21,62-65$ (2012).

17. Schiffman E, Ohrbach R, Truelove E, Look J, Anderson G, Goulet JP et al Diagnostic Criteria for Temporomandibular Disorders (DC/ TMD) for Clinical and Research Applications: recommendations of the International RDC/TMD Consortium Network and Orofacial Pain Special Interest Group. J Oral Facial Pain Headach

18. Lamot U, Strojan P, Popopiv KS. Magnetic resonance imaging of temporomandibular joint dysfunction - correlation with clinical symptoms, age, and gender. Oral Surg Oral Med Oral Pathol Oral Radiol 2013;116: 258-63

19. Guarda-Nardini L, Piccotti F, Mogno G, Favero L, Manfredini D. Age-related differ- ences in temporomandibular disorder diag-noses. Cranio 2012;30:103-9.

20. Poveda Roda R, Bagan JV, Díaz Fernández JM, et al. Review of temporomandibular joint pathology. Part I: classification, epidemiology and risk factors. Med Oraln Pathol Oral Cir Bucal. 2007;12:E292E298

21. Le Resche L, Drangsholt M. Epidemiology of orofacial pain: prevalence, incidence, and risk factors. In: Sessle BJ, Lavigne GJ, Lund JP, et al., editors. Orofacial pain: from basic science to clinical management. Chicago (IL) Quintessence Publications; 2008. p. 13-18

22. Chisnoiu AM, Picos AM, Popa S, et al. Factors involved in the etiology of temporomandibular 
disorders - a literature review. Clujul Med. 2015;88:473-478

23. Dao T T, Le Resche L. Gender differences in pain. J Orofa Pain Summer 2000;14(3):169-84; discussion 184-95

24. Bueno CH, Pereira DD, Pattussi MP, et al. Gender differences in temporomandibular disorders in adult populational studies: A systematic review and meta-analysis. J Oral Rehabil. 2018;45(9) 720-729

25. L€ovgren A, H€aggman-Henrikson B, Visscher $\mathrm{CM}$, et al. Temporomandibular pain and jaw dysfunction at different agescovering the lifespan - a population based study. Eur J Pain.2016;20(4):532540.

26. Sessle BJ, Lavigne GJ, Lund JP, et al. Orofacial pain. From Basic Science to Clinical Management. 2nd ed. Chicago: Quintessence Publishing; 2008. p. $1-264$.

27. Poveda Roda R, Bagan JV, Díaz Fernández JM, et al. Review of temporomandibular joint pathology. Part I: classification, epidemiology and risk factors. Med Oraln Pathol Oral Cir Bucal. 2007;12:E292E298

28. Le Resche L, Drangsholt M. Epidemiology of orofacial pain: prevalence, incidence, and risk factors. In: Sessle BJ, Lavigne GJ, Lund JP, et al., editors. Orofacial pain: from basic science to clinical management. Chicago (IL) Quintessence Publications; 2008. p. 13-18

29. Qvintus, V., Sipilä, K., Le Bell, Y., \& Suominen, A. L. (2020). Prevalence of clinical signs and pain symptoms of temporomandibular disorders and associated factors in adult Finns. Acta Odontologica Scandinavica, 1-7. doi:10.1080/00016357.2020.17 46395

30. Dawson PE. Position paper regarding diagnosis, management, and treatment of temporomandibular disorders. The American Equilibration Society. J Prosthet Dent. 1999 Feb;81(2):174-8.

31. Carey JP, Craig M, Kerstein RB, Radke J. Determining a relationship between applied occlusal load and articulating paper mark area. Open Dent J. 2007;1:1-7.

32. Kerstein R, Radke J. Clinician accuracy when subjectively interpreting articulating paper markings. Cranio. 2014 Jan;32(3):13-23.

33. Maness WL, Benjamin M, Podoloff R, Bobick A,Golden RF. Computerized occlusal analysis: a newtechnology. Quintessence Int 1987;18:287-92

34. Santana-Mora U, Cudeiro J, Mora-Bermúdez MJ, Rilo- B, Ferreira-Pinho JC, Otero-Cepeda $\mathrm{JL}$, et al. Changes in EMG activity during clenching in chronic pain patients with unilateral temporomandibular disorders. J Electromyogr Kinesiol 2009;19:e543-9.

35. Karan Abrol and Sakshi Abrol .T- Scan - The dental advisor. International Journal of Applied Dental Sciences 2019; 5(2): 2

36. Ciavarella D, Mastrovincenzo M, Sabatucci A, Parziale V, Granatelli F, Violante F, Bossù M, Lo Muzio L, Chimenti C. Clinical and computerized evaluation in study of temporo-mandibular joint intracapsular disease. Minerva Stomatol. 2010 Mar;59(3):89-101.

37. Qadeer, S., Abbas, A. A., Sarinnaphakorn, L., \& Kerstein, R. B. (2016). Comparison of excursive occlusal force parameters in post-orthodontic and non-orthodontic subjects using T-Scan ${ }^{\circledR}$ III. CRANIO®, 36(1), 11-18. doi:10.1080/08869634. 2016.1259785

38. Thumati P, Manwani R, Mahantshetty M. The effect of reduced Disclusion Time in the treatment of myofascial pain dysfunction syndrome using immediate complete anterior guidance development protocol monitored by digital analysis of occlusion. Cranio. 2014 Oct;32(4):289-99. PMID: 25252768

39. Baladin, Nota A, Cozza P. The association between occlusion time and temporomandibular disorders. J Electromyogr Kinesiol. 2015;25(1):15-154

40. Wang, C., \& Yin, X. (2012). Occlusal risk factors associated with temporomandibular disorders in young adults with normal occlusions. Oral Surgery, Oral Medicine, Oral Pathology and Oral Radiology, 114(4), 419-423. doi:10.1016/j.oooo.2011.10.039

41. Agne Dzingute*, Gaivile Pileicikiene, Ausra Baltrusaityte. Digital occlusal evaluation in patients with temporomandibular joint disorders. Dzingute A, Pileicikiene G, Baltrusaityte A. Digital occlusal evaluation in patients with temporomandibular joint disorders. Mol Med Ther. 2017;1(1):8-13.

42. Satheesh B. Haralur. Digital Evaluation of Functional Occlusion Parameters and their Association with Temporomandibular Disorders. Journal of Clinical and Diagnostic Research. 2013 Aug, Vol-7(8): 1772-1775. 